\title{
Aberrant structural and functional connectivity and neurodevelopmental impairment in preterm children
}

\author{
Cynthia E. Rogers ${ }^{1 *}$ D, Rachel E. Lean ${ }^{2}$, Muriah D. Wheelock ${ }^{2}$ and Christopher D. Smyser ${ }^{3}$
}

\begin{abstract}
Background: Despite advances in antenatal and neonatal care, preterm birth remains a leading cause of neurological disabilities in children. Infants born prematurely, particularly those delivered at the earliest gestational ages, commonly demonstrate increased rates of impairment across multiple neurodevelopmental domains. Indeed, the current literature establishes that preterm birth is a leading risk factor for cerebral palsy, is associated with executive function deficits, increases risk for impaired receptive and expressive language skills, and is linked with higher rates of co-occurring attention deficit hyperactivity disorder, anxiety, and autism spectrum disorders. These same infants also demonstrate elevated rates of aberrant cerebral structural and functional connectivity, with persistent changes evident across advanced magnetic resonance imaging modalities as early as the neonatal period. Emerging findings from cross-sectional and longitudinal investigations increasingly suggest that aberrant connectivity within key functional networks and white matter tracts may underlie the neurodevelopmental impairments common in this population.

Main body: This review begins by highlighting the elevated rates of neurodevelopmental disorders across domains in this clinical population, describes the patterns of aberrant structural and functional connectivity common in prematurely-born infants and children, and then reviews the increasingly established body of literature delineating the relationship between these brain abnormalities and adverse neurodevelopmental outcomes. We also detail important, typically understudied, clinical, and social variables that may influence these relationships among preterm children, including heritability and psychosocial risks.

Conclusion: Future work in this domain should continue to leverage longitudinal evaluations of preterm infants which include both neuroimaging and detailed serial neurodevelopmental assessments to further characterize relationships between imaging measures and impairment, information necessary for advancing our understanding of modifiable risk factors underlying these disorders and best practices for improving neurodevelopmental trajectories in this high-risk clinical population.
\end{abstract}

Keywords: Prematurity, Neurodevelopmental disorders, Functional connectivity, Structural connectivity, Magnetic resonance imaging

\footnotetext{
* Correspondence: rogersc@wustl.edu

${ }^{1}$ Departments of Psychiatry and Pediatrics, Washington University School of

Medicine, 660 South Euclid Avenue, Campus Box 8504, St. Louis, MO 63110,

USA

Full list of author information is available at the end of the article
}

(c) The Author(s). 2018 Open Access This article is distributed under the terms of the Creative Commons Attribution 4.0 International License (http://creativecommons.org/licenses/by/4.0/), which permits unrestricted use, distribution, and reproduction in any medium, provided you give appropriate credit to the original author(s) and the source, provide a link to the Creative Commons license, and indicate if changes were made. The Creative Commons Public Domain Dedication waiver (http://creativecommons.org/publicdomain/zero/1.0/) applies to the data made available in this article, unless otherwise stated. 
Preterm birth remains a major public health issue due to its high incidence combined with the frequency of neurodevelopmental impairments among surviving infants. In this review, we begin by highlighting the adverse effects of prematurity on trajectories across neurodevelopmental domains. Next, we discuss the increasingly established relationship between aberrant brain development and preterm birth, with particular focus on the advanced magnetic resonance imaging (MRI) techniques increasingly utilized to delineate the changes in cerebral structural and functional connectivity related to prematurity. We then review selected studies from the extant literature which suggest that prematurity-associated changes in cerebral structural and functional connectivity may underlie the neurodevelopmental impairments common among prematurely born children and adults. Finally, we conclude by detailing relevant clinical and social variables that may influence these relationships in this high-risk clinical population.

\section{Prematurity and neurodevelopmental disorders}

Premature birth affects more than 500,000 newborns in the USA each year, occurring in approximately $10 \%$ of all births in 2016 [1]. Survival rates for these infants have improved dramatically due to advances in perinatal and neonatal care. In contrast to this improvement in mortality, long-term neurodevelopmental outcomes have not improved, with preterm birth remaining a leading cause of neurological disabilities in children [2]. These surviving preterm children face a range of neurodevelopmental and neurobehavioral challenges [3-7], with more than $30 \%$ experiencing impairments across multiple neurodevelopmental domains [8]. Children delivered very preterm (VPT; born at $\leq 32$ weeks' gestation) typically face disproportionate risk, with infants born earliest facing the highest rates of developmental disability [9]. However, these adverse effects are not universal, with widely varied outcomes among preterm children with similar neonatal clinical phenotypes. Critically, the associated costs in caring for these children are enormous, amounting to more than $\$ 25$ billion annually in the USA alone [10].

Among preterm children, prominent neurodevelopmental difficulties are seen across motor, cognitive, language, and social-emotional domains [11-14]. These areas warrant particular focus due not only to their critical functional importance, but also to their significant impact on quality of life, including poor peer relationships [15] and academic underachievement [16-18]. Over $50 \%$ of children diagnosed with cerebral palsy are born preterm, with the greatest likelihood among those born at the earliest gestational ages [19]. An even larger proportion of preterm children experience other more subtle fine and gross motor problems, with approximately $40 \%$ displaying mild to moderate motor impairment [12]. Similarly, 15-20\% of intellectual disabilities and $10-15 \%$ of other learning disorders are attributable to preterm birth. VPT children obtain Full Scale Intelligence Quotient (IQ) scores up to 10 points lower than term children $[20,21]$. Furthermore, VPT children consistently perform worse than term-born peers on executive function tasks assessing planning, fluency, working memory, and response inhibition [22-24]. Preterm children also demonstrate problems in selective, sustained, and executive attention, with up to $41 \%$ of VPT and $62 \%$ of extremely preterm (born at $<28$ weeks' gestation) children in the impaired range [25-28]. Further, large effect sizes have been reported for executive shifting and divided attention [25, 26, 29], suggesting VPT children particularly struggle with top-down control of attention processes. In addition, approximately $35 \%$ of children born between 31 and 34 weeks' gestation demonstrate language impairments at preschool-age, with rates as high as $48 \%$ for children born at less than 30 weeks gestation [30]. Deficits in both receptive and expressive language domains persist into school age, affecting skills such as word finding, perception, grammar, dialog, and linguistics [30-34]. Critically, across each of these neurodevelopmental domains, preterm birth remains a strong risk factor for impairment even after accounting for sociodemographic risk [19, 35].

More recently, elevated rates of social-emotional deficits and psychiatric disorders have been recognized among children born preterm, with increasing numbers of reports detailing the "preterm behavioral phenotype" [36], comprised of inattention, anxiety, and social-communication deficits [37]. These comorbid symptoms and the related disorders of Attention-deficit hyperactivity disorder (ADHD), anxiety, and autism spectrum disorder (ASD) are two to four times more common among preterm children [5, 38-43]. As with other neurodevelopmental impairments, children born VPT are at greatest risk for these social-emotional impairments and psychiatric diagnoses [36]. Further, studies examining the trajectory of these symptoms demonstrate their persistence into adolescence [5, 44-49]. Importantly, rates of these disorders remain elevated even after accounting for the increased frequency of other neurodevelopmental disabilities, including motor and intellectual impairments [36].

\section{Assessment of functional and structural connectivity in preterm children using MRI}

The timing of key interrelated neurobiological processes underlying development of early cerebral functional and structural connectivity make the preterm brain uniquely vulnerable to the perturbations that have been associated with common neurodevelopmental disorders. Most notably, this includes processes such as neuronal migration, synaptogenesis, cortical folding, emergence of thalamo-cortical 
connections, and myelination [50]. Early investigations of children born preterm employed conventional MRI to characterize the alterations in cerebral structural development associated with preterm birth [51-55]. These predominantly cross-sectional investigations focused on metrics of brain growth, regional brain volumes, and cortical folding, demonstrating atypical patterns of maturation throughout the brain across techniques in preterm children [56-58]. However, these modalities provided only limited ability to elucidate the alterations in cerebral development that lead to neurodevelopmental deficits; information critical for understanding the pathway to disability.

Advanced MRI techniques, including resting statefunctional MRI (rs-fMRI) and diffusion MRI (dMRI), provide powerful, non-invasive tools with high sensitivity for delineating alterations in the developing brain. rs-fMRI is used to detect temporal correlations in spontaneous, low-frequency fluctuations in blood oxygen level-dependent signal, thereby identifying functional connectivity networks from data acquired without requiring subjects to perform tasks during acquisition [59-61]. These resting state networks incorporate gray matter regions known to be anatomically connected and co-activated by task performance [60, 62, 63]. dMRI characterizes cerebral structural connectivity through quantification of water displacement within the white matter microstructural architecture [64-66]. In many ways, these modalities are well-suited for investigations of infants and pediatric populations; from a study lasting minutes in duration on an infant at rest, robust measures of global functional and structural connectivity can be obtained. Further, both modalities have been used successfully to investigate cerebral connectivity in VPT adults and older pediatric populations, demonstrating atypical connectivity patterns which correlate with neurodevelopmental disability [57, 67-71].

Unique methodological challenges have now been overcome to successfully study neonates and young children using rs-fMRI and dMRI, including scan sequence specification, scanning of non-sedated subjects, effects of small brain sizes on atlas registration, and development of data processing streams [72-75]. Our group and others have subsequently used these techniques to identify immature forms of multiple canonical resting state networks and white matter tracts throughout the brain as early as 26 weeks postmenstrual age (PMA). These systems reflect the functional and structural topography of the developing brain, gradually maturing with advancing age [74]. Our recent applications of rs-fMRI and dMRI demonstrate infants possess a functional and structural network architecture similar to that described in adults, with maturation rates emulating known histological evidence regarding brain development [74, 76, 77]. For example, networks (e.g., somatomotor, auditory, visual networks) and tracts (e.g., corticospinal tracts, optic radiations) in areas of the brain known to develop early demonstrate mature topology by term equivalent PMA. In contrast, networks (e.g., default mode [DMN], frontoparietal [FPN], cingulo-opercular $[\mathrm{CO}]$ networks), and tracts (e.g., cingulum bundle, uncinate) located in higher-order association cortices involved in top-down control of emotion regulation, attention, and cognition do not demonstrate adult-like topology until later in life.

Further, these methods are sensitive to the changes in functional and structural connectivity associated with premature birth (Fig. 1). Across rs-fMRI investigations, infants born prematurely demonstrate similar overall resting state network topography to term-born infants scanned at comparable PMA, though with weaker intrinsic brain activity. The magnitude of these differences in network amplitude and dimensionality differ by network and are typically most prominent in those located in higher-order association cortices [74, 77, 78]. Infants with forms of white matter injury common in preterm populations (e.g., intraventricular hemorrhage, cystic periventricular leukomalacia) demonstrate aberrant network development, dependent upon severity and proximity to the injury site [79]. Interrelated investigations of structural connectivity using dMRI also demonstrate comparable regionally specific differences in gray and white matter microstructural development between preterm and term-born infants [80-86]. Across these studies, prematurely born infants demonstrate delayed white matter tract development, with susceptibility to specific clinical factors (e.g., antenatal steroids, white matter injury) also reported. Further, these neuroimaging data are conducive to technically sophisticated analysis approaches designed to investigate complex patterns in neuroimaging data, such as graph theory and machine learning [76, 87-91]. Use of these methods in neonates and older pediatric populations have demonstrated the importance of connectivity within and between networks for differentiation of term- and prematurely born infants and continuous measure (i.e., birth gestational age) prediction [92-94]. These studies provide converging lines of evidence suggesting neurodevelopmental impairment may directly correlate with disruptions in specific structural and functional systems.

\section{Prematurity-related changes in functional and structural connectivity and developmental impairment}

There is a small, but burgeoning literature investigating the relationship between cerebral functional and structural connectivity changes and motor, cognitive, language, and social-emotional outcomes in prematurely born children [54, 58, 81, 95-103]. For brevity, across each of these domains, we highlight 
A
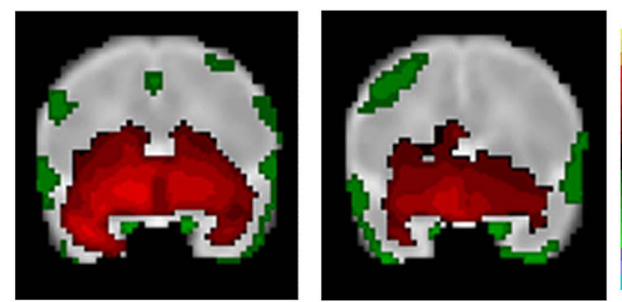

B
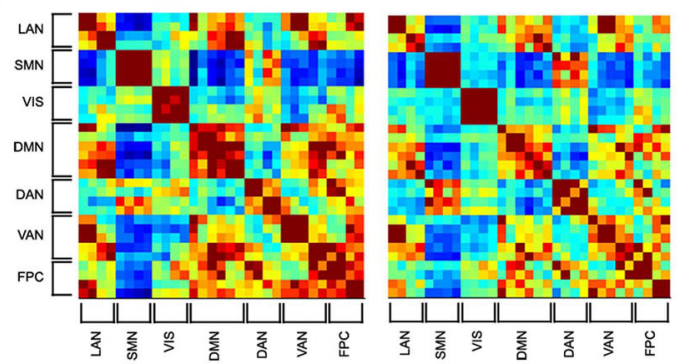

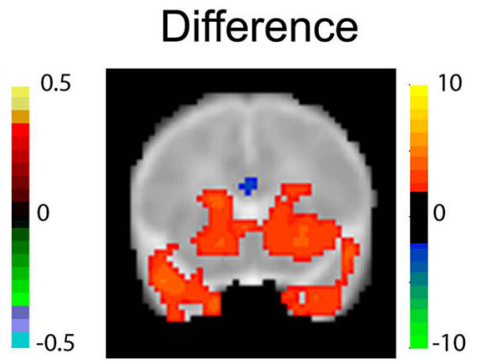

\section{Preterm}

C
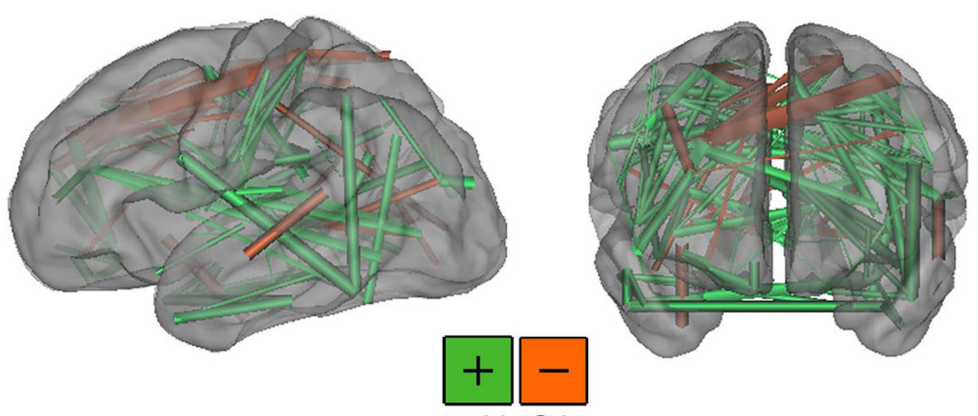

with GA

Fig. 1 Functional connectivity differences between term and very preterm infants. a Left: group mean amygdala resting state-functional connectivity correlation maps for full-term and very preterm infants scanned at term equivalent postmenstrual age; right: $z$ scores demonstrating group differences in connectivity obtained from voxelwise $t$ test. Blue voxels denote areas with greater negative correlations and orange voxels denote areas with greater positive correlations in term infants. Results thresholded using $|z|>2.25$ and 53 contiguous voxels achieving whole-brain false-positive rate of 0.05. Adapted with permission from Rogers CE, et al. JAACAP. 2017; 56(2):157-166. b Left: group mean covariance matrices representing multiple canonical RSNs for full-term and very preterm infants at term equivalent postmenstrual age; right: difference between these two results (term minus preterm). Black stars denote cells with between group difference on two-tailed Mann-Whitney $U$ test ( $p<0.05$; multiple comparisons uncorrected). Adapted with permission from Smyser CD, et al. Cerebral Cortex. 2016; 26(1):322-333. c Functional connections important for differentiating full-term versus very preterm infants using support vector machine-multivariate pattern analysis to analyze data from 244 regions of interest located throughout the brain. Connections stronger in term infants are shown in green; those stronger in very preterm infants are in orange. The caliber of each

connection is weighted by the difference magnitude. Adapted with permission from Smyser CD, et al. Neurolmage. 2016; 136:1-9

representative studies which have served to increasingly identify the links between measures of aberrant brain connectivity and adverse neurodevelopmental outcomes, beginning during the neonatal period and extending into adulthood. As the methods for application of the modality were established earlier, many of these studies utilized dMRI, though an increasing number of recent studies also include rs-fMRI. Further, many of these investigations have been cross-sectional and focused on older populations, though longitudinal investigations including neonatal data are now being published.

\section{Motor}

dMRI and rs-fMRI have been increasingly used to demonstrate clinically relevant alterations in key white matter tracts and the motor network in prematurely born infants and children. Recently, higher mean and radial diffusivity within the splenium of the corpus callosum and lower fractional anisotropy (FA) in the left inferior temporal lobe in VPT infants, indicating delayed and/or aberrant tract development, were associated with worse motor functioning at age 2 years (Fig. 2) [81, 99]. Similar longitudinal relationships persist into later childhood, as VPT infants with decreased neonatal FA in inferior 

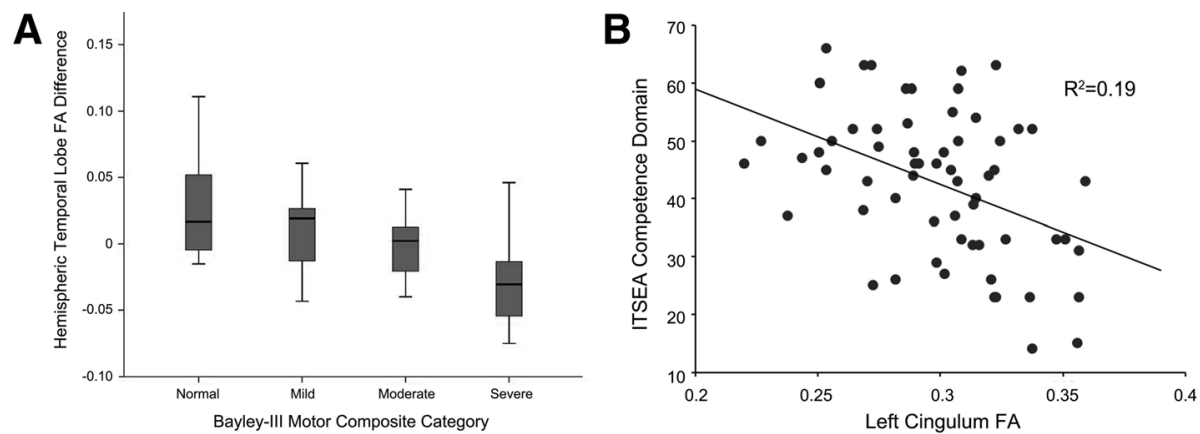

Fig. 2 Relationship between regional neonatal structural connectivity measures and developmental outcomes in preterm children. a Boxplots of hemispheric asymmetry between neonatal left and right inferior temporal lobe white matter fractional anisotropy in very preterm infants scanned at term-equivalent age and Bayley-III Motor Composite Categories based upon assessments performed at age 2 years, corrected. $\mathbf{b}$ Regression plot demonstrating the relationship between fractional anisotropy in the left cingulum bundle at term-equivalent age and competence scores on the Infant Toddler Social Emotional Assessment (ITSEA) tool at age 2 years, corrected. Note the association between more impaired (lower) ITSEA competence scores and higher FA ( $p=.001)$. Adapted with permission from Rogers CE, et al. Pediatric Research. 2016; 79(1-1):87-95

occipital and cerebellar regions demonstrated greater motor impairments at age 7 years [100]. Further, at age 7, VPT children with a higher degree of motor impairment demonstrated reduced structural connectivity within the precuneus, inferior parietal cortex, and temporal lobes in a network-based analysis [101]. Comparable patterns are present in adulthood, with preterm-born adults found to have lower FA in the corpus callosum, inferior longitudinal fasciculus, inferior fronto-occipital fasciculus, and external capsule demonstrating worse visual-motor integration and motor abilities [104]. White matter injury affects these brain-behavior relationships, with motor-impaired VPT children with moderate-severe white matter injury demonstrating lower corpus callosum FA than VPT children with normal motor outcomes at age 7 [105]. Further, children with periventricular leukomalacia and gross motor impairment demonstrated reduced corticospinal tract size [106] and decreased FA within the corticospinal tract and cerebellar peduncles [107]. Similar findings have been reported using rs-fMRI, with investigations of prematurely born children, adolescents, and adults with spastic diplegic cerebral palsy due to periventricular leukomalacia demonstrating aberrant motor network connectivity in relation to term-born peers that correlated with severity of motor impairment $[108,109]$.

\section{Cognitive}

Alterations in cerebral white matter microstructure identified using dMRI have also been linked to adverse cognitive outcomes in preterm children [101, 110-112]. A recent prospective longitudinal study including serial dMRI scans in preterm infants at birth, term equivalent PMA and 2 and 4 years demonstrated that slower rates of change in mean diffusivity (MD) of the internal and external capsules from birth to age 4, also reflecting delayed and/or aberrant tract development, were associated with poorer intellectual ability at age 4 [112]. In addition to these neonatal findings, reduced FA in the uncinate fasciculus, corticospinal tract, cingulum bundle, inferior frontal fasciculus, inferior frontal-occipital fasciculus, superior longitudinal fasciculus, and anterior thalamic radiations has also been associated with worse intellectual and/or executive function skills in preterm children and adolescents $[110,111]$. Further, VPT children with cognitive impairment demonstrate reduced connections in a white matter network including the thalamus, hippocampus, paracentral lobule, posterior cingulate, parietal and occipital cortices, and frontal and temporal gyri compared to non-impaired preterm children in a network-based analysis of white matter structural connectivity graphs [101].

\section{Language}

Multiple studies have also linked aberrant structural and functional cerebral development with poor language outcomes in preterm children. A serial MRI study reported that greater increases in axonal diffusivity of the left posterior thalamic radiation from term-equivalent PMA to age 4 years was associated with poorer receptive and expressive language ability at age 4 [112]. Higher MD in the centrum semiovale and left superior temporal gyrus has also been linked to poorer language outcomes in preterm children $[113,114]$. Consistent with these early childhood findings, alterations in the uncinate fasciculus, splenium of the corpus callosum, and anterior commissure explained up to $57 \%$ of variability in language outcomes among preterm adolescents [115]. Recent rs-fMRI investigations have also shown that preterm children and adolescents demonstrate persisting alterations in language networks compared to term-born peers [116]. Specifically, preterm children demonstrate increased connectivity strength between the language network and other regions throughout the brain, with decreased right hemisphere 
lateralization [117, 118]. These differences have been related to language performance, with preterm adolescents demonstrating weaker bilateral connectivity between left and right superior temporal regions also demonstrating poorer language ability at age 14-15 years $[115,116]$, with other regionally specific relationships also reported $[68,119,120]$.

\section{Social-emotional}

Symptoms of ADHD, anxiety, and ASD comprising the preterm behavioral phenotype have also been linked to altered neonatal structural and functional connectivity in key brain regions [96, 121-142]. Recent evidence suggests that preterm birth may predispose children to higher rates of emotion dysregulation and social-emotional disorders due to stress experienced during the NICU hospitalization via changes in hypothalamic-pituitary-adrenal axis function [143-146] and brain connectivity [73, 147]. For instance, alterations in connectivity of the glucocorticoidrich amygdala [148], which has a prominent role in emotion processing [149-151], have been linked to NICU stress exposure in preterm infants [147]. It has also been shown that neonatal rs-fMRI measures between the amygdala and regions of key cortical networks, including the DMN, FPN, and CO, are related to variability in anxiety symptoms in VPT infants at 2 years (Fig. 3) [152, 153]. Aberrant dMRI measures of white matter tracts related to ADHD, anxiety, and ASD symptoms, such as frontostriatal circuits and frontolimibic regions including the cingulum and uncinate [96, 131-135], have also been associated with these same symptom domains in VPT children [81, 98, 154].

Overall, these lines of converging evidence relating functional and structural connectivity to neurodevelopmental outcomes in preterm children indicate that for early developing white matter tracts and functional networks there are typically well-defined, regionally specific relationships between aberrant connectivity and domain-specific neurodevelopmental impairment. In contrast, abnormalities in tracts connecting key regions within functional networks such as the DMN, FPN, and CO, including the corpus callosum, uncinate, and cingulum, have been linked to impairment across multiple domains. In combination, these results suggest that alterations in structural connectivity underlie the abnormal functional connectivity patterns identified in preterm children, though in a tract- and network-specific manner, and that these differences play a critical role in the increased rates of adverse outcomes in this high-risk clinical population. Further, this work highlights our evolving understanding of the interrelationship between early structural and functional connectivity and the deleterious effects of preterm birth on brain development and neurodevelopmental outcomes.

\section{Clinical variables linked to developmental impairment in preterm children}

While the highlighted research suggests that prematurity-associated alterations in structural and functional connectivity underlie neurodevelopmental impairments in preterm children, other clinical and social factors likely modify this risk. Two important considerations include sociodemographic risk factors and heritability. Preterm children experience higher rates of sociodemographic risk factors known to be associated with developmental deficits, with preterm birth disproportionately occurring among mothers from socially disadvantaged backgrounds $[155,156]$. The odds of VPT delivery are 1.03-1.27 times higher in mothers living below the poverty threshold [157-159], with these mothers typically having low levels of education and high levels of assistance from public health care programs [156, 160, 161]. Among VPT children, poverty is a particularly strong predictor of cognitive, motor, and language outcomes [162-171]. Other psychosocial risk factors more common among preterm infants, including maternal depression [172, 173], high parenting stress $[174,175]$, and unsupportive maternal-child interactions [176-178], have also been linked to adverse psychiatric outcomes [179-187]. For example, we reported maternal depression during early childhood-mediated risk for
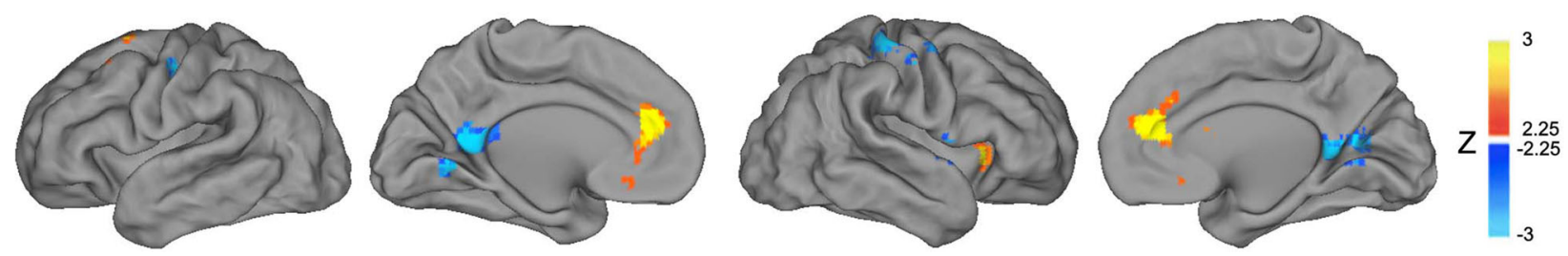

Fig. 3 Relationship between neonatal amygdala functional connectivity and social-emotional outcomes in preterm children. Results from wholebrain analysis investigating the relationship between neonatal functional connectivity of left amygdala and internalizing scores on the Infant Toddler Social Emotional Assessment (ITSEA) tool at age 2 years, corrected. Images demonstrate higher total internalizing domain scores were positively correlated with functional connectivity measures between the left amygdala and the medial prefrontal cortex, right anterior insula, and superior frontal cortex. Results thresholded using $|z|>2.25$ and 53 contiguous voxels achieving whole-brain false-positive rate of 0.05 . Adapted with permission from Rogers CE, et al. JAACAP. 2017; 56(2):157-166 
anxiety disorders associated with preterm birth [188]. In addition, these same risk factors have been linked to changes in brain development, with exposure to poverty and unsupportive caregiving impacting functional and structural brain development in offspring [186, 189-191]. Thus, preterm birth both increases the likelihood of experiencing early psychosocial adversity and alters functional and structural development of the neonatal brain. Further, the developing brain may remain highly vulnerable to continued alterations from repeated exposures to psychosocial adversity extending beyond the neonatal period.

Another key and understudied risk factor among preterm children is heritability. Studies investigating heritability suggest that family background determines the lower and upper limits of the range in which a heritable and continuously distributed trait may be expressed, but that neurodevelopmental disorders increase the phenotypic variability of trait expression during childhood [192, 193]. For instance, maternal intellectual ability has a direct influence on her children's intellectual development because it is a genetically based and heritable trait [194]. Preterm children born to mothers with low levels of intellectual ability may therefore be at higher risk of poor outcomes. Indeed, our analysis of maternal intellectual ability demonstrated that maternal IQ scores were associated with both preterm and term child IQ and language scores at age 5 years [195]. However, the association between maternal IQ and child IQ and language outcomes was weaker for preterm children, indicating preterm birth itself was an important factor explaining intellectual and language development. Further, heritability is an important variable for social-emotional development and psychiatric symptoms underlying the preterm behavioral phenotype, as ADHD, ASD, and anxiety symptoms are all highly heritable [196-199]. In some cases, the heritability of social-emotional symptoms may confound the relationship between prematurity and social-emotional development. For instance, substance-abusing mothers are more likely to both have ADHD [200, 201] and anxiety [202] and to deliver preterm [203, 204]. A similar relationship could exist between the highly related variables of maternal depression and both preterm delivery [205] and childhood anxiety [206]. These findings highlight the need to assess psychosocial risk factors and heritability among families in all research investigating links between preterm birth and neurodevelopmental outcomes.

\section{Future directions and conclusions}

Continued research remains necessary to both further delineate the relationships between imaging measures and neurodevelopmental impairment in prematurely born children and better characterize the role of modifiable risk factors such as psychosocial adversity in this trajectory. While MRI affords several advantages for studying these associations, including improved spatial resolution and anatomic specificity, future investigations may utilize other complementary modalities for assessing brain development and function. These include functional near infrared spectroscopy (fNIRS), which measures hemodynamic contrasts [207-209] and electroencephalography (EEG), which assesses the coherence of cortical electrical activity and has been used to successfully model brain connectivity-behavior associations [210]. In addition, diffuse optical tomography (DOT) enables measurements of functional connectivity which align with rs-fMRI, though with a more limited field of view [211, 212]. Limitations notwithstanding, these portable methods can be readily employed to perform serial studies at the bedside, providing avenues for novel investigation by enabling the study of clinical populations of interest unable to undergo MRI.

Future work should also focus on extending longitudinal evaluations of preterm children across early childhood, leveraging recent advances in MRI acquisition and analysis methods and incorporating advances developed and implemented among other clinical populations. For example, the Infant Brain Imaging Study has performed longitudinal MRI scanning of infants at risk for autism beginning at 6 months of age with repeat MRI scans at 12 and 24 months, reporting changes in both structural and functional connectivity parameters utilizing longitudinal analyses of brain development and innovative brain-behavior analyses $[127,213]$. More recently, the UNC/UMN Baby Connectome Project (BCP), building on sequence development from the Human Connectome Project, is studying longitudinal brain development across the first 5 years of life, including imaging preschool-age children in an awake state [214]. The BCP aims to provide innovative data regarding early typical structural and functional brain development through improved acquisition resolution, optimized diffusion sequences, and frequent longitudinal sampling across early childhood. While substantive technical challenges remain, including best practices for studying children in the setting of evolving tissue contrast and registration of individual imaging data sets across multiple time points, these methods are being increasingly established and can be employed at most institutions.

Collectively, the studies reviewed here and elsewhere [215] provide converging evidence suggesting neurodevelopmental disabilities common in prematurely born children directly relate to early disruptions and/or remodeling of specific functional and structural networks [102]. Continued use of advanced neuroimaging techniques in combination with detailed serial neurodevelopmental assessments as part of longitudinal studies of 
preterm brain development has great potential to advance the field of developmental neuroimaging. Critically, these studies will provide improved understanding of the aberrant trajectories of structural and functional connectivity in prematurely born children and the role of these differences in adverse outcomes. Further, these investigations will provide valuable insights into how psychosocial and familial factors impact not only neonatal brain development, but also the nature and evolution of subsequent alterations during early childhood. Ultimately, this information will prove valuable for both advancing our understanding of modifiable factors underlying these disorders and defining best practices for improving neurodevelopmental trajectories in this high-risk population.

\section{Abbreviations \\ ADHD: Attention-deficit hyperactivity disorder; ASD: Autism spectrum disorder; CO: Cingulo-opercular network; DMN: Default mode network; dMRI: Diffusion magnetic resonance imaging; FA: Fractional anisotropy; FPN: Frontoparietal network; IQ: Intelligence quotient; MD: Mean diffusivity; MRI: Magnetic resonance imaging; PMA: Postmenstrual age; rs-fMRI: Resting state-functional magnetic resonance imaging; VPT: Very preterm}

\section{Acknowledgements}

Not applicable

\section{Funding}

This work was supported by the National Institutes of Health (grant numbers R01 MH113570, K23 MH105179, K02 NS089852, T32 MH100019-02, U54 HD087011, and UL1 TR000448) and the Doris Duke Charitable Foundation. Child Neurology Foundation.

Cerebral Palsy International Research Foundation.

The Dana Foundation.

\section{Availability of data and materials}

Not applicable.

\section{Authors' contributions}

CER and CDS made substantial contributions to the conception and design of the review, were involved in drafting the review and critically revised the review for important intellectual content. REL and MDW were involved in drafting the review and critically revised the review for important intellectual content. All authors read and approved the final submitted review.

\section{Ethics approval and consent to participate}

Not applicable.

\section{Consent for publication}

Not applicable.

\section{Competing interests}

The authors declare that they have no competing interests.

\section{Publisher's Note}

Springer Nature remains neutral with regard to jurisdictional claims in published maps and institutional affiliations.

\section{Author details}

'Departments of Psychiatry and Pediatrics, Washington University School of Medicine, 660 South Euclid Avenue, Campus Box 8504, St. Louis, MO 63110, USA. ${ }^{2}$ Departments of Psychiatry, Washington University School of Medicine, 660 South Euclid Avenue, Campus Box 8504, St. Louis, MO 63110, USA. ${ }^{3}$ Departments of Neurology, Pediatrics and Mallinckrodt Institute of Radiology, Washington University School of Medicine, 660 South Euclid Avenue, Campus Box 8111, St. Louis, MO 63110, USA.
Received: 27 December 2017 Accepted: 14 November 2018 Published online: 13 December 2018

\section{References}

1. Martin J, Hamilton B, Osterman MJK, et al. Births in the United States, 2016. In: NCHS data brief, no 287. Hyattsville: National Center for Health Statistics; 2017.

2. Mwaniki MK, Atieno M, Lawn JE, Newton CRJC. Long-term neurodevelopmental outcomes after intrauterine and neonatal insults: a systematic review. Lancet Lond Engl. 2012;379:445-52.

3. Anderson P, Doyle LW. Neurobehavioral outcomes of school-age children born extremely low birth weight or very preterm in the 1990s. JAMA. 2003; 289:3264-72.

4. Aylward GP. Cognitive and neuropsychological outcomes: more than IQ scores. Ment Retard Dev Disabil Res Rev. 2002;8:234-40.

5. Johnson S, Hollis C, Kochhar P, Hennessy E, Wolke D, Marlow N. Psychiatric disorders in extremely preterm children: longitudinal finding at age 11 years in the EPICure study. J Am Acad Child Adolesc Psychiatry. 2010;49:453-463.e1.

6. Marlow N, Wolke D, Bracewell MA, Samara M, EPICure Study Group. Neurologic and developmental disability at six years of age after extremely preterm birth. N Engl J Med. 2005;352:9-19.

7. Taylor GH, Klein NM, Minich NM, Hack M. Verbal memory deficits in children with less than $750 \mathrm{~g}$ birth weight. Child Neuropsychol J Norm Abnorm Dev Child Adolesc. 2000;6:49-63.

8. Woodward L, Moor S, Hood KM, Champion PR, Foster-Cohen S, Inder TE, et al. Very preterm children show impairments across multiple neurodevelopmental domains by age 4 years. Arch Dis Child Fetal Neonatal Ed. 2009;94:F339-44.

9. Saigal S, Doyle LW. An overview of mortality and sequelae of preterm birth from infancy to adulthood. Lancet. 2008;371:261-9.

10. Behrman RE, Butler AS. Preterm birth: causes, consequences, and prevention. Washington: National Academies Press (US); 2007. http://www. ncbi.nlm.nih.gov/books/NBK11362/. Accessed 27 Nov 2018.

11. Davis NM, Ford GW, Anderson PJ, Doyle LW, Victorian Infant Collaborative Study Group. Developmental coordination disorder at 8 years of age in a regional cohort of extremely-low-birthweight or very preterm infants. Dev Med Child Neurol. 2007;49:325-30.

12. Williams J, Lee KJ, Anderson PJ. Prevalence of motor-skill impairment in preterm children who do not develop cerebral palsy: a systematic review. Dev Med Child Neurol. 2010;52:232-7.

13. Johnson S, Matthews R, Draper ES, Field DJ, Manktelow BN, Marlow N, et al. Early emergence of delayed social competence in infants born late and moderately preterm. J Dev Behav Pediatr. 2015;36:690-9.

14. Barre N, Morgan A, Doyle LW, Anderson PJ. Language abilities in children who were very preterm and/or very low birth weight: a meta-analysis. J Pediatr. 2011;158:766-774.e1

15. Durkin K, Conti-Ramsden G. Language, social behavior, and the quality of friendships in adolescents with and without a history of specific language impairment. Child Dev. 2007:78:1441-57.

16. Conti-Ramsden G, Durkin K, Simkin Z, Knox E. Specific language impairment and school outcomes. I: identifying and explaining variability at the end of compulsory education. Int J Lang Commun Disord. 2009;44:15-35.

17. Horwood L, Mogridge N, Darlow B. Cognitive, educational, and behavioural outcomes at 7 to 8 years in a national very low birthweight cohort. Arch Dis Child Fetal Neonatal Ed. 1998;79:F12-20.

18. Litt J, Taylor HG, Klein N, Hack M. Learning disabilities in children with very low birthweight: prevalence, neuropsychological correlates, and educational interventions. J Learn Disabil. 2005;38:130-41.

19. Schieve LA, Tian LH, Rankin K, Kogan MD, Yeargin-Allsopp M, Visser S, et al. Population impact of preterm birth and low birth weight on developmental disabilities in US children. Ann Epidemiol. 2016;26:267-74.

20. Kerr-Wilson CO, Mackay DF, Smith GCS, Pell JP. Meta-analysis of the association between preterm delivery and intelligence. J Public Health Oxf Engl. 2012;34:209-16.

21. Mangin $\mathrm{KS}$, Horwood $\mathrm{L}$, Woodward $\mathrm{L}$. Cognitive development trajectories of very preterm and typically developing children. Child Dev. 2017;18(1):282-98.

22. Aarnoudse-Moens CSH, Duivenvoorden HJ, Weisglas-Kuperus N, Van Goudoever JB, Oosterlaan J. The profile of executive function in very preterm children at 4 to 12 years. Dev Med Child Neurol. 2012;54:247-53.

23. Anderson PJ, Doyle LW. Executive functioning in school-aged children who were born very preterm or with extremely low birth weight in the 1990s. Pediatrics. 2004;114:50-7. 
24. Woodward LJ, Clark CAC, Pritchard VE, Anderson PJ, Inder TE. Neonatal white matter abnormalities predict global executive function impairment in children born very preterm. Dev Neuropsychol. 2011;36:22-41.

25. Anderson PJ, De Luca CR, Hutchinson E, Spencer-Smith MM, Roberts G, Doyle LW, et al. Attention problems in a representative sample of extremely preterm/extremely low birth weight children. Dev Neuropsychol. 2011;36: 57-73.

26. Lean R, Melzer T, Bora S, Watts R, Woodward L. Attention and regional gray matter development in very preterm children at age 12 years. J Int Neuropsychol Soc. 2017:23(7):539-50.

27. Murray AL, Scratch SE, Thompson DK, Inder TE, Doyle LW, Anderson JFI, et al. Neonatal brain pathology predicts adverse attention and processing speed outcomes in very preterm and/or very low birth weight children. Neuropsychology. 2014;28:552-62.

28. Delane L, Campbell C, Bayliss DM, Reid C, Stephens A, French N, et al. Poorer divided attention in children born very preterm can be explained by difficulty with each component task, not the executive requirement to dualtask. Child Neuropsychol. 2017;23:1-13.

29. Bayless S, Stevenson J. Executive functions in school-age children born very prematurely. Early Hum Dev. 2007:83:247-54.

30. Vieira MEB, Linhares MBM. Developmental outcomes and quality of life in children born preterm at preschool- and school-age. J Pediatr. 2011;87:281-91.

31. Foster-Cohen SH, Friesen MD, Champion PR, Woodward LJ. High prevalence/low severity language delay in preschool children born very preterm. J Dev Behav Pediatr JDBP. 2010;31:658-67.

32. Reidy N, Morgan A, Thompson DK, Inder TE, Doyle LW, Anderson PJ. Impaired language abilities and white matter abnormalities in children born very preterm and/or very low birth weight. J Pediatr. 2013;162:719-24.

33. Wolke D, Samara M, Bracewell M, Marlow N, EPICure Study Group. Specific language difficulties and school achievement in children born at 25 weeks of gestation or less. J Pediatr. 2008;152:256-62.

34. Soleimani F, Zaheri F, Abdi F. Long-term neurodevelopmental outcome s after preterm birth. Iran Red Crescent Med J. 2014;16. https://doi.org/10. 5812/ircmj.17965.

35. Pritchard VE, Bora S, Austin NC, Levin KJ, Woodward LJ. Identifying very preterm children at educational risk using a school readiness framework. Pediatrics. 2014;134:e825-32.

36. Johnson S, Marlow N. Preterm birth and childhood psychiatric disorders. Pediatr Res. 2011;69(5 Pt 2):11R-8R.

37. Montagna A, Nosarti C. Socio-emotional development following very preterm birth: pathways to psychopathology. Front Psychol. 2016;7:80.

38. Spittle AJ, Treyvaud K, Doyle LW, Roberts G, Lee KJ, Inder TE, et al. Early emergence of behavior and social-emotional problems in very preterm infants. J Am Acad Child Adolesc Psychiatry. 2009;48:909-18.

39. Burnett AC, Anderson PJ, Cheong J, Doyle LW, Davey CG, Wood SJ. Prevalence of psychiatric diagnoses in preterm and full-term children, adolescents and young adults: a meta-analysis. Psychol Med. 2011;41:2463-74.

40. Shum D, Neulinger K, O'Callaghan M, Mohay H. Attentional problems in children born very preterm or with extremely low birth weight at 7-9 years. Arch Clin Neuropsychol Off J Natl Acad Neuropsychol. 2008;23:103-12.

41. Indredavik MS, Vik T, Heyerdahl S, Kulseng S, Brubakk A-M. Psychiatric symptoms in low birth weight adolescents, assessed by screening questionnaires. Eur Child Adolesc Psychiatry. 2005;14:226-36.

42. Hack M, Taylor HG, Schluchter M, Andreias L, Drotar D, Klein N. Behavioral outcomes of extremely low birth weight children at age 8 years. J Dev Behav Pediatr JDBP. 2009;30:122-30.

43. Elgen I, Sommerfelt K, Markestad T. Population based, controlled study of behavioural problems and psychiatric disorders in low birthweight children at 11 years of age. Arch Dis Child Fetal Neonatal Ed. 2002;87:F128-32.

44. Breeman LD, Jaekel J, Baumann N, Bartmann P, Wolke D. Attention problems in very preterm children from childhood to adulthood: the Bavarian Longitudinal Study. J Child Psychol Psychiatry. 2016;57:132-40.

45. Treyvaud K, Ure A, Doyle LW, Lee KJ, Rogers CE, Kidokoro H, et al. Psychiatric outcomes at age seven for very preterm children: rates and predictors. J Child Psychol Psychiatry. 2013;54:772-9.

46. Taylor HG, Margevicius S, Schluchter M, Andreias L, Hack M. Persisting behavior problems in extremely low birth weight adolescents. J Dev Behav Pediatr JDBP. 2015;36:178-87.

47. Bora S, Pritchard VE, Chen Z, Inder TE, Woodward LJ. Neonatal cerebral morphometry and later risk of persistent inattention/hyperactivity in children born very preterm. J Child Psychol Psychiatry. 2014;55:828-38.
48. Hall J, Wolke D. A comparison of prematurity and small for gestational age as risk factors for age 6-13 year emotional problems. Early Hum Dev. 2012; 88:797-804.

49. Bohnert KM, Breslau N. Stability of psychiatric outcomes of low birth weight: a longitudinal investigation. Arch Gen Psychiatry. 2008;65:1080-6.

50. Bystron I, Blakemore C, Rakic P. Development of the human cerebral cortex: Boulder Committee revisited. Nat Rev Neurosci. 2008;9:110-22.

51. Eikenes L, Løhaugen GC, Brubakk A-M, Skranes J, Håberg AK. Young adults born preterm with very low birth weight demonstrate widespread white matter alterations on brain DTI. Neurolmage. 2011;54:1774-85.

52. Mullen KM, Vohr BR, Katz KH, Schneider KC, Lacadie C, Hampson M, et al. Preterm birth results in alterations in neural connectivity at age 16 years. Neurolmage. 2011;54:2563-70.

53. Nagae L, Hoon AH, Stashinko E, Lin D, Zhang W, Levey E, et al. Diffusion tensor imaging in children with periventricular leukomalacia: variability of injuries to white matter tracts. Am J Neuroradiol. 2007;28:1213-22.

54. Schafer RJ, Lacadie C, Vohr B, Kesler SR, Katz KH, Schneider KC, et al. Alterations in functional connectivity for language in prematurely born adolescents. Brain J Neurol. 2009;132(Pt 3):661-70.

55. Skranes J, Vangberg TR, Kulseng S, Indredavik MS, Evensen KA, Martinussen $\mathrm{M}$, et al. Clinical findings and white matter abnormalities seen on diffusion tensor imaging in adolescents with very low birth weight. Brain J Neurol. 2007;130(Pt 3):654-66

56. Gimenez M, Soria-Pastor S, Junque C, Caldu X, Narberhaus A, Botet F, et al. Proton magnetic resonance spectroscopy reveals medial temporal metabolic abnormalities in adolescents with history of preterm birth. Pediatr Res. 2008;64:572-7.

57. Gozzo Y, Vohr B, Lacadie C, Hampson M, Katz KH, Maller-Kesselman J, et al. Alterations in neural connectivity in preterm children at school age. Neurolmage. 2009;48:458-63.

58. Nosarti C, Shergill SS, Allin MP, Walshe M, Rifkin L, Murray RM, et al. Neural substrates of letter fluency processing in young adults who were born very preterm: alterations in frontal and striatal regions. Neurolmage. 2009;47: 1904-13.

59. Biswal B, Yetkin FZ, Haughton VM, Hyde JS. Functional connectivity in the motor cortex of resting human brain using echo-planar MRI. Magn Reson Med. 1995;34:537-41.

60. Fox MD, Snyder AZ, Vincent JL, Corbetta M, Van Essen DC, Raichle ME. The human brain is intrinsically organized into dynamic, anticorrelated functional networks. Proc Natl Acad Sci U S A. 2005;102:9673-8.

61. Lowe MJ, Mock BJ, Sorenson JA. Functional connectivity in single and multislice echoplanar imaging using resting-state fluctuations. Neurolmage. 1998;7:119-32.

62. Smith SM, Fox PT, Miller KL, Glahn DC, Fox PM, Mackay CE, et al. Correspondence of the brain's functional architecture during activation and rest. Proc Natl Acad Sci. 2009;106:13040-5.

63. Zhang D, Raichle ME. Disease and the brain's dark energy. Nat Rev Neurol. 2010;6:15-28.

64. McKinstry RC, Mathur A, Miller JH, Ozcan A, Snyder AZ, Schefft GL, et al. Radial Organization of Developing Preterm Human Cerebral Cortex Revealed by non-invasive water diffusion anisotropy MRI. Cereb Cortex. 2002;12:1237-43.

65. Neil JJ, Shiran SI, McKinstry RC, Schefft GL, Snyder AZ, Almli CR, et al. Normal brain in human newborns: apparent diffusion coefficient and diffusion anisotropy measured by using diffusion tensor MR imaging. Radiology. 1998;209:57-66.

66. Neil J, Miller J, Mukherjee P, Hüppi PS. Diffusion tensor imaging of normal and injured developing human brain - a technical review. NMR Biomed. 2002;15:543-52

67. Wheelock MD, Austin NC, Bora S, Eggebrecht AT, Melzer TR, Woodward L, Smyser CD. Altered functional network connectivity relates to motor development in children born very preterm. Neurolmage. 2018;183:574-83.

68. Constable RT, Vohr BR, Scheinost D, Benjamin JR, Fulbright RK, Lacadie C, et al. A left cerebellar pathway mediates language in prematurely-born young adults. Neurolmage. 2013;64:371-8.

69. Caldinelli C, Froudist-Walsh S, Karolis V, Tseng C-E, Allin MP, Walshe M, Cuddy M, Murray RM, Nosarti C. White matter alterations to cingulum and fornix following very preterm birth and their relationship with cognitive function. Neurolmage. 2017;150:373-82.

70. Myers EH, Hampson M, Vohr B, Lacadie C, Frost SJ, Pugh KR, et al. Functional connectivity to a right hemisphere language center in prematurely born adolescents. Neurolmage. 2010;51:1445-52. 
71. Wingert JR, Sinclair RJ, Dixit S, Damiano DL, Burton H. Somatosensoryevoked cortical activity in spastic diplegic cerebral palsy. Hum Brain Mapp. 2010;31:1772-85.

72. Pineda RG, Neil J, Dierker D, Smyser CD, Wallendorf M, Kidokoro H, et al. Alterations in brain structure and neurodevelopmental outcome in preterm infants hospitalized in different neonatal intensive care unit environments. J Pediatr. 2014;164:52-60.e2

73. Smith GC, Gutovich J, Smyser C, Pineda R, Newnham C, Tjoeng TH, et al. Neonatal intensive care unit stress is associated with brain development in preterm infants. Ann Neurol. 2011;70:541-9.

74. Smyser CD, Inder TE, Shimony JS, Hill JE, Degnan AJ, Snyder AZ, et al. Longitudinal analysis of neural network development in preterm infants. Cereb Cortex. 2010;20:2852-62.

75. Smyser CD, Snyder AZ, Neil JJ. Functional connectivity MRI in infants: exploration of the functional organization of the developing brain. Neurolmage. 2011;56:1437-52.

76. Smyser CD, Dosenbach NUF, Smyser TA, Snyder AZ, Rogers CE, Inder TE, et al. Prediction of brain maturity in infants using machine-learning algorithms. Neurolmage. 2016;136:1-9.

77. Smyser CD, Snyder AZ, Shimony JS, Mitra A, Inder TE, Neil JJ. Resting-state network complexity and magnitude are reduced in prematurely born infants. Cereb Cortex N Y N 1991. 2016;26:322-33.

78. Toulmin H, Beckmann CF, O'Muircheartaigh J, Ball G, Nongena P, Makropoulos A, et al. Specialization and integration of functional thalamocortical connectivity in the human infant. Proc Natl Acad Sci. 2015; 112:6485-90.

79. Smyser CD, Snyder AZ, Shimony JS, Blazey TM, Inder TE, Neil JJ. Effects of white matter injury on resting state fMRI measures in prematurely born infants. PLoS One. 2013;8:e68098.

80. Smyser TA, Smyser CD, Rogers CE, Gillespie SK, Inder TE, Neil JJ. Cortical gray and adjacent white matter demonstrate synchronous maturation in very preterm infants. Cereb Cortex N Y N 1991. 2016;26:3370-8.

81. Rogers CE, Smyser T, Smyser CD, Shimony J, Inder TE, Neil JJ. Regional white matter development in very preterm infants: perinatal predictors and early developmental outcomes. Pediatr Res. 2015. https://doi.org/10.1038/pr.2015.172.

82. Duerden EG, Card D, Lax ID, Donner EJ, Taylor MJ. Alterations in frontostriatal pathways in children born very preterm. Dev Med Child Neurol. 2013;55(10):952-8.

83. Pannek K, Hatzigeorgiou X, Colditz PB, Rose S. Assessment of structural connectivity in the preterm brain at term equivalent age using diffusion MRI and t2 relaxometry: a network-based analysis. PLoS One. 2013;8:e68593.

84. Thompson DK, Inder TE, Faggian N, Johnston L, Warfield SK, Anderson PJ, et al. Characterization of the corpus callosum in very preterm and full-term infants utilizing MRI. Neurolmage. 2011;55:479-90.

85. Pavaine J, Young JM, Morgan BR, Shroff M, Raybaud C, Taylor MJ. Diffusion tensor imaging-based assessment of white matter tracts and visual-motor outcomes in very preterm neonates. Neuroradiology. 2016;58(3):301-10.

86. Skiöld B, Horsch S, Hallberg B, Engström M, Nagy Z, Mosskin M, et al. White matter changes in extremely preterm infants, a population-based diffusion tensor imaging study. Acta Paediatr Oslo Nor 1992. 2010;99:842-9.

87. Dosenbach NUF, Nardos B, Cohen AL, Fair DA, Power JD, Church JA, et al. Prediction of individual brain maturity using fMRI. Science. 2010;329:1358-61.

88. Erus G, Battapady H, Satterthwaite TD, Hakonarson H, Gur RE, Davatzikos C et al. Imaging patterns of brain development and their relationship to cognition. Cereb Cortex N Y N 1991. 2015;25:1676-84.

89. Greene DJ, Church JA, Dosenbach NUF, Nielsen AN, Adeyemo B, Nardos B, et al. Multivariate pattern classification of pediatric Tourette syndrome using functional connectivity MRI. Dev Sci. 2016;19:581-98.

90. Magnin B, Mesrob L, Kinkingnéhun S, Pélégrini-Issac M, Colliot O, Sarazin M, et al. Support vector machine-based classification of Alzheimer's disease from whole-brain anatomical MRI. Neuroradiology. 2009;51:73-83.

91. Pruett JR, Kandala S, Hoertel S, Snyder AZ, Elison JT, Nishino T, et al. Accurate age classification of 6 and 12 month-old infants based on restingstate functional connectivity magnetic resonance imaging data. Dev Cogn Neurosci. 2015;12:123-33.

92. Ben-Hur A, Ong CS, Sonnenburg S, Schölkopf B, Rätsch G. Support vector machines and kernels for computational biology. PLoS Comput Biol. 2008;4: e1000173.

93. Ecker C, Rocha-Rego V, Johnston P, Mourao-Miranda J, Marquand A, Daly EM, et al. Investigating the predictive value of whole-brain structural MR scans in autism: a pattern classification approach. Neurolmage. 2010;49:44-56.
94. Pereira F, Mitchell T, Botvinick M. Machine learning classifiers and fMRI: a tutorial overview. Neurolmage. 2009;45(1 Suppl):S199-209.

95. Bäuml JG, Meng C, Daamen M, Baumann N, Busch B, Bartmann P, et al. The association of children's mathematic abilities with both adults' cognitive abilities and intrinsic fronto-parietal networks is altered in preterm-born individuals. Brain Struct Funct. 2017;222(2):799-812.

96. Counsell SJ, Edwards AD, Chew ATM, Anjari M, Dyet LE, Srinivasan L, et al. Specific relations between neurodevelopmental abilities and white matter microstructure in children born preterm. Brain J Neurol. 2008;131(Pt 12): 3201-8.

97. De Bruïne FT, Van Wezel-Meijler G, Leijser LM, Steggerda SJ, Van Den BergHuysmans AA, Rijken M, et al. Tractography of white-matter tracts in very preterm infants: a 2-year follow-up study. Dev Med Child Neurol. 2013;55(5):427-33.

98. Rogers CE, Anderson PJ, Thompson DK, Kidokoro H, Wallendorf M, Treyvaud $\mathrm{K}$, et al. Regional cerebral development at term relates to school-age socialemotional development in very preterm children. J Am Acad Child Adolesc Psychiatry. 2012;51:181-91.

99. Thompson DK, Inder TE, Faggian N, Warfield SK, Anderson PJ, Doyle LW, et al. Corpus callosum alterations in very preterm infants: perinatal correlates and 2 year neurodevelopmental outcomes. Neurolmage. 2012;59: 3571-81.

100. Thompson DK, Lee KJ, Egan GF, Warfield SK, Doyle LW, Anderson PJ, et al. Regional white matter microstructure in very preterm infants: predictors and 7 year outcomes. Cortex J Devoted Study Nerv Syst Behav. 2014;52:60-74.

101. Thompson DK, Chen J, Beare R, Adamson CL, Ellis R, Ahmadzai ZM, et al. Structural connectivity relates to perinatal factors and functional impairment at 7years in children born very preterm. Neurolmage. 2016;134:328-37.

102. Ure AM, Treyvaud K, Thompson DK, Pascoe L, Roberts G, Lee KJ, et al. Neonatal brain abnormalities associated with autism spectrum disorder in children born very preterm. Autism Res Off J Int Soc Autism Res. 2016;9(5):543-52.

103. van Kooij BJM, de Vries LS, Ball G, van Haastert IC, Benders MJNL, Groenendaal F, et al. Neonatal tract-based spatial statistics findings and outcome in preterm infants. AJNR Am J Neuroradiol. 2012;33:188-94.

104. Sripada K, Løhaugen GC, Eikenes L, Bjørlykke KM, Håberg AK, Skranes J, et al. Visual-motor deficits relate to altered gray and white matter in young adults born preterm with very low birth weight. Neurolmage. 2015;109:493-504.

105. Estep ME, Smyser CD, Anderson PJ, Ortinau CM, Wallendorf M, Katzman CS, et al. Diffusion tractography and neuromotor outcome in very preterm children with white matter abnormalities. Pediatr Res. 2014;76:86-92.

106. Rha D, Chang WH, Kim J, Sim EG, Park ES. Comparing quantitative tractography metrics of motor and sensory pathways in children with periventricular leukomalacia and different levels of gross motor function. Neuroradiology. 2012;54:615-21.

107. Wang S, Fan GG, Xu K, Wang C. Altered microstructural connectivity of the superior and middle cerebellar peduncles are related to motor dysfunction in children with diffuse periventricular leucomalacia born preterm: a DTI tractography study. Eur J Radiol. 2014;83:997-1004

108. Lee JD, Park H-J, Park ES, Oh M-K, Park B, Rha D-W, et al. Motor pathway injury in patients with periventricular leucomalacia and spastic diplegia. Brain. 2011;134:1199-210.

109. Burton H, Dixit S, Litkowski P, Wingert JR. Functional connectivity for somatosensory and motor cortex in spastic diplegia. Somatosens Mot Res. 2009;26:90-104.

110. Murray AL, Thompson DK, Pascoe L, Leemans A, Inder TE, Doyle LW, et al. White matter abnormalities and impaired attention abilities in children born very preterm. Neurolmage. 2016;124:75-84.

111. Vollmer B, Lundequist A, Martensson G, Nagy Z, Lagercrantz H, Smedler A-C, et al. Correlation between white matter microstructure and executive functions suggests early developmental influence on long fiber tracts in preterm born adolescents. PLoS One. 2017;12:e0179993.

112. Young JM, Morgan BR, Whyte HEA, Lee W, Smith ML, Raybaud C, et al. Longitudinal study of white matter development and outcomes in children born very preterm. Cereb Cortex. 2017;27(8):4094-105.

113. Aeby $A$, De Tiège $X$, Creuzil $M$, David $P$, Balériaux $D$, Van Overmeire $B$, et al. Language development at 2 years is correlated to brain microstructure in the left superior temporal gyrus at term equivalent age: a diffusion tensor imaging study. Neurolmage. 2013;78:145-51.

114. Pogribna U, Burson K, Lasky RE, Narayana PA, Evans PW, Parikh NA. Role of diffusion tensor imaging as an independent predictor of cognitive and language development in extremely low-birth-weight infants. AJNR Am J Neuroradiol. 2014;35:790-6. 
115. Northam GB, Liégeois F, Tournier J-D, Croft LJ, Johns PN, Chong WK, et al. Interhemispheric temporal lobe connectivity predicts language impairment in adolescents born preterm. Brain J Neurol. 2012;135(Pt 12):3781-98.

116. Wilke M, Hauser T-K, Krägeloh-Mann I, Lidzba K. Specific impairment of functional connectivity between language regions in former early preterms. Hum Brain Mapp. 2014;35:3372-84.

117. Kwon SH, Vasung L, Ment LR, Huppi PS. The role of neuroimaging in predicting neurodevelopmental outcomes of preterm neonates. Clin Perinatol. 2014;41:257-83.

118. Scheinost D, Lacadie C, Vohr BR, Schneider KC, Papademetris X, Constable $\mathrm{RT}$, et al. Cerebral lateralization is protective in the very prematurely born. Cereb Cortex. 2015;25:1858-66.

119. White TP, Symington I, Castellanos NP, Brittain PJ, Froudist Walsh S, Nam K$W$, et al. Dysconnectivity of neurocognitive networks at rest in very-preterm born adults. Neurolmage Clin. 2014;4:352-65.

120. Scheinost D, Benjamin J, Lacadie C, Vohr B, Schneider K, Ment L, et al. The intrinsic connectivity distribution: a novel contrast measure reflecting voxel level functional connectivity. Neurolmage. 2012;62:1510-9.

121. Castellanos FX, Proal E. Large-scale brain systems in ADHD: beyond the prefrontal-striatal model. Trends Cogn Sci. 2012;16:17-26.

122. de Zeeuw P, Mandl RCW, Hulshoff Pol HE, van Engeland H, Durston S. Decreased frontostriatal microstructural organization in attention deficit/ hyperactivity disorder. Hum Brain Mapp. 2012;33:1941-51.

123. Wu Y, Gau SS, Lo Y, Tseng WI. White matter tract integrity of frontostriatal circuit in attention deficit hyperactivity disorder: association with attention performance and symptoms. Hum Brain Mapp. 2014;35(1):199-212.

124. Casey BJ, Nigg JT, Durston S. New potential leads in the biology and treatment of attention deficit-hyperactivity disorder. Curr Opin Neurol. 2007;20:119-24.

125. Koechlin E, Ody C, Kouneiher F. The architecture of cognitive control in the human prefrontal cortex. Science. 2003;302:1181-5

126. Cheon K-A, Kim Y-S, Oh S-H, Park S-Y, Yoon H-W, Herrington J, et al. Involvement of the anterior thalamic radiation in boys with high functioning autism spectrum disorders: a diffusion tensor imaging study. Brain Res. 2011;1417:77-86.

127. Wolff JJ, Gu H, Gerig G, Elison JT, Styner M, Gouttard S, et al. Differences in white matter fiber tract development present from 6 to 24 months in infants with autism. Am J Psychiatry. 2012;169:589-600.

128. Dawson G, Bernier R, Ring RH. Social attention: a possible early indicator of efficacy in autism clinical trials. J Neurodev Disord. 2012;4:11.

129. Chevallier C, Kohls G, Troiani V, Brodkin ES, Schultz RT. The social motivation theory of autism. Trends Cogn Sci. 2012;16:231-9.

130. Albaugh M, Ducharme S, Karama S, Watts R, Lewis J, Orr C, Hudziak J. Anxious/ depressed symptoms are related to microstructural maturation of white matter in typically developing youths. Dev Psychopathol. 2017;29(3):751-58.

131. Makris N, Buka SL, Biederman J, Papadimitriou GM, Hodge SM, Valera EM, et al. Attention and executive systems abnormalities in adults with childhood ADHD: a DT-MRI study of connections. Cereb Cortex N Y N 1991. 2008;18:1210-20

132. Shukla DK, Keehn B, Müller R-A. Tract-specific analyses of diffusion tensor imaging show widespread white matter compromise in autism spectrum disorder. J Child Psychol Psychiatry. 2011;52:286-95.

133. Billeci L, Calderoni S, Tosetti M, Catani M, Muratori F. White matter connectivity in children with autism spectrum disorders: a tract-based spatial statistics study. BMC Neurol. 2012;12:148.

134. Silk TJ, Vance A, Rinehart N, Bradshaw JL, Cunnington R. White-matter abnormalities in attention deficit hyperactivity disorder: a diffusion tensor imaging study. Hum Brain Mapp. 2009;30:2757-65.

135. Solso S, Xu R, Proudfoot J, Hagler DJ, Campbell K, Venkatraman V, et al. Diffusion tensor imaging provides evidence of possible axonal overconnectivity in frontal lobes in autism Spectrum disorder toddlers. Biol Psychiatry. 2016;79:676-84

136. Roy AK, Fudge JL, Kelly C, Perry JSA, Daniele T, Carlisi C, et al. Intrinsic functional connectivity of amygdala-based networks in adolescent generalized anxiety disorder. J Am Acad Child Adolesc Psychiatry. 2013;52:290-299.e2.

137. Qin S, Young CB, Duan X, Chen T, Supekar K, Menon V. Amygdala subregional structure and intrinsic functional connectivity predicts individual differences in anxiety during early childhood. Biol Psychiatry. 2014:75:892-900

138. Maier SJ, Szalkowski A, Kamphausen S, Feige B, Perlov E, Kalisch R, et al. Altered cingulate and amygdala response towards threat and safe cues in attention deficit hyperactivity disorder. Psychol Med. 2014;44:85-98.
139. Rausch A, Zhang W, Haak KV, Mennes M, Hermans EJ, van Oort E, et al. Altered functional connectivity of the amygdaloid input nuclei in adolescents and young adults with autism spectrum disorder: a resting state fMRI study. Mol Autism. 2016;7:13.

140. Kim MJ, Gee DG, Loucks RA, Davis FC, Whalen PJ. Anxiety dissociates dorsal and ventral medial prefrontal cortex functional connectivity with the amygdala at rest. Cereb Cortex. 2011;21:1667-73.

141. Hamm LL, Jacobs RH, Johnson MW, Fitzgerald DA, Fitzgerald KD, Langenecker SA, et al. Aberrant amygdala functional connectivity at rest in pediatric anxiety disorders. Biol Mood Anxiety Disord. 2014;4:15.

142. Andreescu C, Mennin D, Tudorascu D, Sheu LK, Walker S, Banihashemi L, et al. The many faces of anxiety-neurobiological correlates of anxiety phenotypes. Psychiatry Res. 2015;234:96-105.

143. Weinstock M. The long-term behavioural consequences of prenatal stress. Neurosci Biobehav Rev. 2008;32:1073-86.

144. Brummelte S, Chau CMY, Cepeda IL, Degenhardt A, Weinberg J, Synnes AR, et al. Cortisol levels in former preterm children at school age are predicted by neonatal procedural pain-related stress. Psychoneuroendocrinology. 2015;51:151-63.

145. Grunau RE, Holsti L, Haley DW, Oberlander T, Weinberg J, Solimano A, et al. Neonatal procedural pain exposure predicts lower cortisol and behavioral reactivity in preterm infants in the NICU. Pain. 2005;113:293-300.

146. Provenzi L, Giusti L, Fumagalli M, Tasca H, Ciceri F, Menozzi G, et al. Painrelated stress in the neonatal intensive care unit and salivary cortisol reactivity to socio-emotional stress in 3-month-old very preterm infants. Psychoneuroendocrinology. 2016;72:161-5.

147. Scheinost D, Kwon SH, Lacadie C, Sze G, Sinha R, Constable RT, et al. Prenatal stress alters amygdala functional connectivity in preterm neonates. Neurolmage Clin. 2016;12:381-8.

148. McEwen BS, Nasca C, Gray JD. Stress effects on neuronal structure: Hippocampus, amygdala, and prefrontal cortex. Neuropsychopharmacology. 2016;41:3-23.

149. LeDoux J. The emotional brain, fear, and the amygdala. Cell Mol Neurobiol. 2003:23:727-38

150. Price JL. Comparative aspects of amygdala connectivity. Ann N Y Acad Sci. 2003;985:50-8.

151. LeDoux JE. Emotion circuits in the brain. Annu Rev Neurosci. 2000;23:155-84.

152. Rogers CE, Sylvester CM, Mintz C, Kenley JK, Shimony JS, Barch DM, et al. Neonatal amygdala functional connectivity at rest in healthy and preterm infants and early internalizing symptoms. J Am Acad Child Adolesc Psychiatry. 2017;56:157-66.

153. Sylvester CM, Smyser CD, Smyser T, Kenley J, Ackerman JJ, Shimony JS, et al. Cortical functional connectivity evident after birth and behavioral inhibition at age 2. Am J Psychiatry. 2017. https://doi.org/10.1176/appi.ajp.2017. 17010018

154. Fischi-Gómez E, Vasung L, Meskaldji D-E, Lazeyras F, Borradori-Tolsa C, Hagmann $\mathrm{P}$, et al. Structural brain connectivity in school-age preterm infants provides evidence for impaired networks relevant for higher order cognitive skills and social cognition. Cereb Cortex. 2015;25:2793-805.

155. Brumberg HL, Shah SI. Born early and born poor: an eco-bio-developmental model for poverty and preterm birth. J Neonatal-Perinat Med. 2015;8:179-87.

156. Manuck TA. Racial and ethnic differences in preterm birth: a complex, multifactorial problem. Semin Perinatol. 2017;41(8):511-18.

157. Carmichael SL, Kan P, Padula AM, Rehkopf DH, Oehlert JW, Mayo JA, et al. Social disadvantage and the black-white disparity in spontaneous preterm delivery among California births. PLoS One. 2017;12:e0182862.

158. Miller GE, Culhane J, Grobman W, Simhan H, Williamson DE, Adam EK, et al. Mothers' childhood hardship forecasts adverse pregnancy outcomes: role of inflammatory, lifestyle, and psychosocial pathways. Brain Behav Immun. 2017:65:11-9.

159. Ncube CN, Enquobahrie DA, Albert SM, Herrick AL, Burke JG. Association of neighborhood context with offspring risk of preterm birth and low birthweight: a systematic review and meta-analysis of population-based studies. Soc Sci Med 1982. 2016;153:156-64.

160. Lefmann T, Combs-Orme T, Orme JG. Examining the inter-correlated effects of low income, life stress, and race on birth outcomes: a representative state study. Soc Work Health Care. 2017;56:450-69.

161. Reagan PB, Salsberry PJ. Race and ethnic differences in determinants of preterm birth in the USA: broadening the social context. Soc Sci Med. 2005;60:2217-28.

162. Asztalos EV, Church PT, Riley P, Fajardo C, Shah PS, Canadian Neonatal Network and Canadian Neonatal Follow-up Network Investigators. 
Association between primary caregiver education and cognitive and language development of preterm neonates. Am J Perinatol. 2017;34: 364-71.

163. Linsell L, Malouf R, Morris J, Kurinczuk JJ, Marlow N. Prognostic factors for poor cognitive development in children born very preterm or with very low birth weight: a systematic review. JAMA Pediatr. 2015;169:1162-72.

164. Patra K, Greene MM, Patel AL, Meier P. Maternal education level predicts cognitive, language, and motor outcome in preterm infants in the second year of life. Am J Perinatol. 2016;33:738-44.

165. Vohr BR. Language and hearing outcomes of preterm infants. Semin Perinatol. 2016:40:510-9.

166. Voss W, Jungmann T, Wachtendorf M, Neubauer A. Long-term cognitive outcomes of extremely low-birth-weight infants: the influence of the maternal educational background. Acta Paediatr. 2012;101:569-73.

167. Aylward GP. Update on neurodevelopmental outcomes of infants born prematurely. J Dev Behav Pediatr JDBP. 2014;35:392-3.

168. Ment LR, Vohr B, Allan W, Katz KH, Schneider KC, Westerveld M, et al. Change in cognitive function over time in very low-birth-weight infants. JAMA. 2003;289:705-11.

169. Stoelhorst GMSJ, Rijken M, Martens SE, van Zwieten PHT, Feenstra J, Zwinderman $\mathrm{AH}$, et al. Developmental outcome at 18 and 24 months of age in very preterm children: a cohort study from 1996 to 1997. Early Hum Dev. 2003;72:83-95.

170. Wang L-W, Wang S-T, Huang C-C. Preterm infants of educated mothers have better outcome. Acta Paediatr Oslo Nor 1992. 2008:97:568-73.

171. Yaari M, Mankuta D, Harel-Gadassi A, Friedlander E, Bar-Oz B, EventovFriedman $\mathrm{S}$, et al. Early developmental trajectories of preterm infants. Res Dev Disabil. 2018:81:12-23.

172. Brett K, Barfield W, Williams C. Prevalence of self-reported postpartum depressive symptoms--17 states, 2004-2005. MMWR Morb Mortal Wkly Rep. 2008;57:361-66.

173. Miles MS, Holditch-Davis D, Schwartz TA, Scher M. Depressive symptoms in mothers of prematurely born infants. J Dev Behav Pediatr JDBP. 2007;28:36-44.

174. Singer LT, Salvator A, Guo S, Collin M, Lilien L, Baley J. Maternal psychological distress and parenting stress after the birth of a very lowbirth-weight infant. JAMA J Am Med Assoc. 1999;281:799-805.

175. Gray PH, Edwards DM, O'Callaghan MJ, Cuskelly M, Gibbons K. Parenting stress in mothers of very preterm infants - influence of development, temperament and maternal depression. Early Hum Dev. 2013;89:625-9.

176. Feldman R. Parent-infant synchrony and the construction of shared timing; physiological precursors, developmental outcomes, and risk conditions. J Child Psychol Psychiatry. 2007;48:329-54.

177. Clark CA, Woodward LJ, Horwood LJ, Moor S. Development of emotional and behavioral regulation in children born extremely preterm and very preterm: biological and social influences. Child Dev. 2008;79:1444-62.

178. Montirosso R, Borgatti R, Trojan S, Zanini R, Tronick E. A comparison of dyadic interactions and coping with still-face in healthy pre-term and fullterm infants. Br J Dev Psychol. 2010;28(Pt 2):347-68.

179. Bagner DM, Sheinkopf SJ, Miller-Loncar C, LaGasse LL, Lester BM, Liu J, et al. The effect of parenting stress on child behavior problems in high-risk children with prenatal drug exposure. Child Psychiatry Hum Dev. 2009;40:73-84.

180. Reiss F. Socioeconomic inequalities and mental health problems in children and adolescents: a systematic review. Soc Sci Med 1982. 2013;90:24-31.

181. Shaw DS, Winslow EB, Owens EB, Vondra JI, Cohn JF, Bell RQ. The development of early externalizing problems among children from lowincome families: a transformational perspective. J Abnorm Child Psychol. 1998;26:95-107.

182. Yoshikawa H, Aber JL, Beardslee WR. The effects of poverty on the mental, emotional, and behavioral health of children and youth: implications for prevention. Am Psychol. 2012;67:272-84.

183. Weissman MM, Warner V, Wickramaratne P, Moreau D, Olfson M. Offspring of depressed parents. 10 years later. Arch Gen Psychiatry. 1997;54:932-40.

184. Lewis G, Rice F, Harold GT, Collishaw S, Thapar A. Investigating environmental links between parent depression and child depressive/ anxiety symptoms using an assisted conception design. J Am Acad Child Adolesc Psychiatry. 2011;50:451-459.e1.

185. Rice F, Harold GT, Boivin J, van den Bree M, Hay DF, Thapar A. The links between prenatal stress and offspring development and psychopathology: disentangling environmental and inherited influences. Psychol Med. 2010; 40:335-45.
186. Luby J, Belden A, Botteron K, Marrus N, Harms MP, Babb C, et al. The effects of poverty on childhood brain development: the mediating effect of caregiving and stressful life events. JAMA Pediatr. 2013;167:1135-42.

187. Apter-Levy Y, Feldman M, Vakart A, Ebstein RP, Feldman R. Impact of maternal depression across the first 6 years of life on the child's mental health, social engagement, and empathy: the moderating role of oxytocin. Am J Psychiatry. 2013;170:1161-8.

188. Rogers CE, Lenze SN, Luby JL. Late preterm birth, maternal depression, and risk of preschool psychiatric disorders. J Am Acad Child Adolesc Psychiatry. 2013;52:309-18.

189. Kishiyama MM, Boyce WT, Jimenez AM, Perry LM, Knight RT. Socioeconomic disparities affect prefrontal function in children. J Cogn Neurosci. 2009;21: $1106-15$.

190. Lipina SJ, Posner MI. The impact of poverty on the development of brain networks. Front Hum Neurosci. 2012;6:238.

191. Stevens C, Lauinger B, Neville H. Differences in the neural mechanisms of selective attention in children from different socioeconomic backgrounds: an event-related brain potential study. Dev Sci. 2009;12:634-46.

192. Finucane B, Challman TD, Martin CL, Ledbetter DH. Shift happens: family background influences clinical variability in genetic neurodevelopmental disorders. Genet Med. 2016;18:302-4.

193. Moreno-De-Luca A, Evans DW, Boomer KB, Hanson E, Bernier R, Goin-Kochel $\mathrm{RP}$, et al. The role of parental cognitive, behavioral, and motor profiles in clinical variability in individuals with chromosome 16p11.2 deletions. JAMA Psychiatry. 2015;72:119.

194. Kirkpatrick RM, McGue M, lacono WG, Miller MB, Basu S. Results of a "GWAS plus:" general cognitive ability is substantially heritable and massively polygenic. PLoS One. 2014;9:e112390.

195. Lean RE, Paul RA, Smyser CD, Rogers CE. Maternal intelligence quotient (IQ) predicts IQ and language in very preterm children at age 5 years. J Child Psychol Psychiatry. 2017. https://doi.org/10.1111/jcpp.12810.

196. Trzaskowski M, Zavos HMS, Haworth CMA, Plomin R, Eley TC. Stable genetic influence on anxiety-related behaviours across middle childhood. J Abnorm Child Psychol. 2012;40:85-94.

197. Tick B, Bolton P, Happé F, Rutter M, Rijsdijk F. Heritability of autism spectrum disorders: a meta-analysis of twin studies. J Child Psychol Psychiatry. 2016; 57:585-95.

198. Larsson H, Chang Z, D'Onofrio BM, Lichtenstein P. The heritability of clinically diagnosed attention deficit hyperactivity disorder across the lifespan. Psychol Med. 2014:44:2223-9.

199. Chang Z, Lichtenstein P, Asherson PJ, Larsson H. Developmental twin study of attention problems: high heritabilities throughout development. JAMA Psychiatry. 2013;70:311-8.

200. De Alwis D, Lynskey MT, Reiersen AM, Agrawal A. Attention-deficit/ hyperactivity disorder subtypes and substance use and use disorders in NESARC. Addict Behav. 2014;39:1278-85.

201. Dunne EM, Hearn LE, Rose JJ, Latimer WW. ADHD as a risk factor for early onset and heightened adult problem severity of illicit substance use: an accelerated gateway model. Addict Behav. 2014;39:1755-8.

202. Lai HMX, Cleary M, Sitharthan T, Hunt GE. Prevalence of comorbid substance use, anxiety and mood disorders in epidemiological surveys, 1990-2014: a systematic review and meta-analysis. Drug Alcohol Depend. 2015;154:1-13.

203. Quispel C, Lambregtse-van den Berg MP, Steegers EAP, Hoogendijk WJG, Bonsel GJ. Contribution of psychopathology, psychosocial problems and substance use to urban and rural differences in birth outcomes. Eur J Pub Health. 2014;24:917-23.

204. Quesada O, Gotman N, Howell HB, Funai EF, Rounsaville BJ, Yonkers KA. Prenatal hazardous substance use and adverse birth outcomes. J MaternFetal Neonatal Med Off J Eur Assoc Perinat Med Fed Asia Ocean Perinat Soc Int Soc Perinat Obstet. 2012;25:1222-7.

205. Fransson E, Ortenstrand A, Hjelmstedt A. Antenatal depressive symptoms and preterm birth: a prospective study of a Swedish national sample. Birth Berkeley Calif. 2011;38:10-6.

206. Côté SM, Boivin M, Liu X, Nagin DS, Zoccolillo M, Tremblay RE. Depression and anxiety symptoms: onset, developmental course and risk factors during early childhood. J Child Psychol Psychiatry. 2009;50:1201-8.

207. Hebden JC, Gibson A, Austin T, Yusof RM, Everdell N, Delpy DT, et al. Imaging changes in blood volume and oxygenation in the newborn infant brain using three-dimensional optical tomography. Phys Med Biol. 2004;49: 1117-30. 
208. Hintz SR, Benaron DA, Siegel AM, Zourabian A, Stevenson DK, Boas DA. Bedside functional imaging of the premature infant brain during passive motor activation. J Perinat Med. 2001;29. https//doi.org/10.1515/JPM.2001.048.

209. White BR, Liao SM, Ferradal SL, Inder TE, Culver JP. Bedside optical imaging of occipital resting-state functional connectivity in neonates. Neurolmage. 2012:59:2529-38.

210. Omidvarnia A, Metsäranta M, Lano A, Vanhatalo S. Structural damage in early preterm brain changes the electric resting state networks. Neurolmage. 2015;120:266-73.

211. Ferradal SL, Liao SM, Eggebrecht AT, Shimony JS, Inder TE, Culver JP, et al. Functional imaging of the developing brain at the bedside using diffuse optical tomography. Cereb Cortex. 2016;26:1558-68.

212. Eggebrecht AT, Ferradal SL, Robichaux-Viehoever A, Hassanpour MS, Dehghani $\mathrm{H}$, Snyder AZ, et al. Mapping distributed brain function and networks with diffuse optical tomography. Nat Photonics. 2014:8:448.

213. Marrus N, Eggebrecht AT, Todorov A, Elison JT, Wolff JJ, Cole L, et al. Walking, gross motor development, and brain functional connectivity in infants and toddlers. Cereb Cortex N Y N 1991. 2018;28:750-63.

214. Howell BR, Styner MA, Gao W, Yap P-T, Wang L, Baluyot K, et al. The UNC/ UMN baby connectome project (BCP): an overview of the study design and protocol development. Neurolmage. 2018. https://doi.org/10.1016/j. neuroimage.2018.03.049.

215. Fenoglio A, Georgieff MK, Elison JT. Social brain circuitry and social cognition in infants born preterm. J Neurodev Disord. 2017;9. https://doi. org/10.1186/s1 1689-017-9206-9.

Ready to submit your research? Choose BMC and benefit from:

- fast, convenient online submission

- thorough peer review by experienced researchers in your field

- rapid publication on acceptance

- support for research data, including large and complex data types

- gold Open Access which fosters wider collaboration and increased citations

- maximum visibility for your research: over $100 \mathrm{M}$ website views per year

At BMC, research is always in progress.

Learn more biomedcentral.com/submissions 